\title{
2 The Origins of Queer Festivals in Europe
}

I believe in art and theory and direct action. All these combined, in my mind, create praxis. I can't stop thinking about praxis, about how to engage in it on an everyday basis. Writing and thinking and talking and creating and doing. [...] Read! Go to lectures! Rent documentaries! Go out there and raise your consciousness! Write! Make art! Talk! Get active get active get active!

Does 'praxis', as proclaimed in the Copenhagen Queer Festival, signify a completely new form of political action? In order to reply to this question, we need to contextualize queer festivals into a historical narrative. This chapter functions as a precursor of the debate following. I argue that queer festivals have origins that trace back to the global justice movement, the Queeruption festivals, and US-based queer theory. By drawing upon secondary sources, I sketch an overview of the origins of current queer festivals in Europe. I link, later, this legacy to sociological trends of activists and participants in current queer festivals.

In the first part, I contextualize queer festivals by means of a historic narrative. I link queer festivals to the emergence and development of queer politics in the USA and Europe after the late 1980s. In this part, the global justice legacy of the queer movement in Europe is explored, since it relates directly to the structure and organizational tactics of queer festivals. Furthermore, questions on the definition and translation of queer/queerness/ queering is addressed by exploring the ideological legacy of queer, tracing its roots to the development of the academic discipline of queer theory. In the second part, I expose the social basis of the festivals' participants. Based upon an online survey I conducted at the Oslo Queer Festival, I proceed to conclusions regarding the sociological constituency of the participants at that festival. I suggest, however, that these findings could be generalized to the wider field. According to the survey, the main social basis of the events is constituted by young, educated, middle-class people. Moreover, the survey indicates that the festivals present a dynamic degree of participants' mobility capacities. 


\section{Historical genealogies}

\section{Emergence and development of queer politics in the USA}

Queer activism as a movement distinct from gay and lesbian politics has its roots in the USA in the late 1980 s (Gamson 1995). It was mainly the AIDS crisis that radicalized political trends originating from the gay and lesbian movements of the 1980 os. ACT UP New York is considered the pioneer organization of this political trend. ACT UP, apart from its direct-action, confrontational repertoire, used a radicalized discourse attacking not only state institutions for their indifference towards people suffering from HIV/ AIDS, but also the conservative values of patriarchy, normality and sexism, present in both the heterosexual and the homosexual community (Gamson 1989; Shepard 2010; Warner 1993). Queer Nation followed the same rhetoric and tactics of ACT UP, by proclaiming 'resistance to regimes of the normal as an alternative to identity-based politics of representation' (Brown 2015). SexPanic!, another group in New York City, 'pushe[d] the limits of identitarian politics and allowe[d] for a broader pro-sex agenda by seeking alliances based not on "gayness", but on stigmatized sexual practices [...] [which] may be most threatened by the moral claims of gay conservatives' (Pendleton and Goldschmidt 1998).

These groups were born in a very specific historical and geographical context. New York City provided the symbolic and material space for new forms of politics to emerge. The flourishing gay movement of that period, associated with a vibrant homosexual culture, was based on essentialist conceptualizations of gay identity, which viewed sexuality in the same way as race, and therefore tried to mobilize in the same ways as previous race-based identity politics movements had done (Murray 1979; Corber and Valocchi 2003: 2; Epstein, 1994). ${ }^{2}$ The outbreak of the HIV crisis and its conservative instrumentalization by public authorities, however,

2 The biological determinisms of sexuality still hold a powerful authority in the USA. This essentialist discourse is built upon a clear binary distinction of homosexuality and heterosexuality. It is promoted in the official public sphere, and disseminated through the mass-culture products of American cultural industries. For a critique, see Brandon Ambrosino, who claims that the biological narrative might have helped the LGBT movement at one time, but it is not necessary anymore: 'Arguing that gayness is as genetically fixed as race might have bolstered our rhetoric a few years ago, but is it necessary to argue that way now? I understand that the genetic argument for homosexuality is a direct response to the tired "You weren't born that way" rhetoric of religious people. But in my opinion, we could strip that religious argument of much of its power if we responded like this: "Maybe I wasn't born this way. Now tell me why you think that matters"' (Ambrosino 2014). 
created the opportunity for activists to move away from identity-based movements. ${ }^{3}$ This process took place through abandoning strict sexual identifications and moving towards an oppositional identity; oppositional against the way HIV was instrumentalized by the state and the media in order to increase homophobia. But also in terms of membership: ACT UP New York included heterosexual and homosexual women, HIV-positive and HIV-negative men, and transgender people. At the same time, a new political and epistemological critique started emerging in American universities: queer theory.

\section{Queer theory: The emergence of a discourse on anti-identitarian sexual politics}

New York queer politics emerged in parallel with the development of queer theory within American academia and the legitimization of poststructuralist theories on sexuality. As Gavin Brown explains:

From the very beginning, the development of Queer Theory was entangled with the new breed of queer activism. There were direct overlaps in personnel between the graduate students and early career academics developing queer theoretical approaches and those strategizing and participating in queer direct action on the streets. Queer Theory was rooted in this broader radical project of contesting heteronormative social relations. In the intervening two decades, the relationship between Queer Theory and radical street-based activism has become more tenuous and more strained, but has never been entirely broken. (2015: 73)

Insights from queer theory can reveal important aspects of the queer movement. In fact, queer theory suggested an epistemological rupture with the identity politics model which reigned in sociology and the humanities until the 1990s, according to which 'gays and lesbians constitute an oppressed minority similar to other oppressed minorities such as Jews and African Americans, and they have their distinct history and culture that can be traced to the ancient Greeks' (Corber and Valocchi 2003: 2). Scholars coming mainly from the humanities, such as Judith Butler, Eve Kosofsky Sedgwick and Michael Warner, appropriated critically the poststructuralist

3 The HIV crisis was used as a pretext by the conservative mayor of New York City Rudolph Giugliani to close all private bars in which sexual acts were taking place, such as sex clubs, bath houses, porn stores, etc. (Warner 2000: 153-157). 
approaches of identity put forward by French philosophers such as Michel Foucault, Louis Althusser, Jacques Derrida and Jacques Lacan.

The key book of this flourishing school of thought was Judith Butler's Gender Trouble: Feminism and the Subversion of Identity, published in $1990^{4}$ Butler engaged with feminist theory and constructionist approaches on gender by claiming that identity is not only socially constructed, but also performative. By analysing drag performances, Butler argued that it is specific acts, gestures and enactments that are performative, in the sense that 'the essence or identity that they otherwise purport to express are fabrications manufactured and sustained through corporeal signs and other discursive means (1999: 173; emphasis in the original). Performativity thus is a 'reiterative and citational practice by which discourse produces the effects that it names' (Butler 1993:2). Based on speech/act theory according to which performative is a form of speech that does something, instead of just describing it, Butler moved sexual and gender politics one step forward by considering gender as a "corporeal style, an "act", which is both intentional and performative, where "performative" suggests a dramatic and contingent construction of meaning' (1999: 177; emphasis in the original). As such, gender became 'an identity tenuously constituted in time, instituted in an exterior space through a stylized repetition of acts' (Butler 1999: 179; emphasis in the original). Although the constructed character and performative aspect of gender is accepted now in the humanities and social sciences, Butler shook the foundations of feminism by claiming that it is not only gender which is socially constructed, but also sex, the biological/anatomical organ, the 'raw material' as it has been described (Rubin 1975: 165). ${ }^{5}$ Butler claimed that:

If the immutable character of 'sex' is contested, perhaps this construct called 'sex' is as culturally constructed as gender; indeed, perhaps it was always already gendered, with the consequence that the distinction between sex and gender turns out to be no distinction at all. (1999:10-11)

Therefore, the traditional conception of gender as a social construction and of sex as a biological essence, 'raw material', collapsed with the contributions of Butler and the emergence of queer theory.

4 I use the second edition of Gender Trouble (1999).

5 Contrary to difference feminism (Braidotti 1994) and French psychoanalytic feminism (Irigaray 1993), which both stress emphatically the ontological division between men and women. 
Several social scientists largely engaged with queer theory in a rather constructive and critical approach. Steven Epstein, sociologist back then at the University of California-San Diego, in his article "A Queer Encounter: Sociology and the Study of Sexuality" (1994) argued that the "term queer has recently come into wide use to designate distinctive emphases in the politics and the intellectual study of sexuality" (188). In a rather critical note, he reminds us that the majority of the work we actually call "queer theory" has already to a certain extent been explored by sociology, including social constructivist approaches on sexuality. Epstein recognizes that queer theory would have much to learn from sociology, particularly through its anchoring to the real, contrary to its "textual idealism" (1994: 198). On the other hand, he speaks to sociologists and offers them specific lines of research, paths that queer theory has opened and which sociology should benefit from by engaging with. For example, sociologists could start working on the construction and hierarchizing of sexual meanings and social categorizations (what are the central institutions for the reproduction or challenge of sexual codes and beliefs?), social institutions (how does the state intervene in sexual politics, and how do these constitute these institutions?), and finally social movements (the role of the queer movement in exploring the dynamics of collective action in "new social movements").

Joshua Gamson seems to respond to Epstein's call for further attention of social movement studies to the queer movement. Through empirical work, he observes the emergence of queerness as a distinct identity inside the LGBT community of that time. In his article 'Must Identity Movements Self-Destruct? A Queer Dilemma' (1995), Gamson discussed how the decision to call the 1993 San Francisco Freedom Parade the 'Year of the Queer' sparked an outcry to many gay- and lesbian-identified people that saw an attempt to destroy what older lesbian and gay identity politics had achieved so far.

In later texts, Gamson and Moon acknowledge the influence of queer theory for sociology so that we can understand now that 'sexual identities, desires and categories are fluid and dynamic and that sexuality is inevitably intertwined with [...] power relations' (2004: 49). Corber and Valocchi noted that sociologically the term 'queer' refers to 'identities and practices that foreground the instability inherent in the supposedly stable relationship between anatomical sex, gender and sexual desire' (2003: 1). While queer politics and queer theories marked the activist and the academic scenes in the USA, queer developed in Europe through a distinct process. 


\section{Diffusion of queer politics in Europe}

Queer travel to Europe is a typical case of transnational diffusion, seen as 'processes by which people work to effect social and political change [...] [by] building alliances, exerting pressure, and spreading and adapting knowledge across national borders' (Ayoub 2016: 7). Diffusion, however, does not imply a linear transposition to the new context, but rather a series of discontinuities, retransformations, adaptations and challenges, as happened in Europe. The diffusion of queer in the continent took place rather quickly, but only at the activist level. For academics, queer theory gradually and slowly integrated European academia in different countries (Downing and Gillett 2011), while in some of them it encountered extreme resistance (for France for instance, see Bourcier 2002). Queer theory found its way into European academia, starting mainly in the UK, and in differentiated terms it expanded to Scandinavia, Italy, Germany, etc., adapting in each case to the local context in which it was transposed. In their edited volume Queer in Europe, Downing and Gillett argue that "queer in Europe" does not mean a return to the French theorists who provided the underpinnings to queer's anti-identitarian force' (2011: 4). ${ }^{6}$ The authors suggest that we see queer in Europe as a tool to describe 'the ways in which strategies that we might call "queer" [...] are currently being implemented, discussed, taught or otherwise disseminated in a range of European countries' (Downing and Gillett 2011: 4). Part of various academic programmes, queer theory is nowadays present across Europe, usually in gender studies departments, or in specific courses in the humanities and social sciences.

Concerning queer politics, diffusion started with the creation of ACT UP branches in several European capitals, such as London, Paris and Berlin (Brown 2015). London saw the birth of queer groups, mobilizing against conservative Thatcherite discourses (Bell and Binnie 2000: 44). The prominent one was OutRage!, which drew upon the legacy of ACT UP London and was influenced by the use of direct action protests in response to the government's implementation of Section 28 of the Local Government Act (1988), which prohibited the use of public funds to 'intentionally promote' homosexuality (Brown 2015: 77).

6 Or, as the series editor of the volume argued, we should not see queer as 'a McDonaldizing American exportation' but rather as something which bears 'exciting possibilities, [...] not only for the development of conceptualizations of sexuality, but for broader philosophical questions too' (Downing and Gillett 2011: xv). 
In the French context, ACT UP Paris was an illustrative example of transnational diffusion, 'despite obvious discrepancies between the pluralist political culture in the United States and their own political culture of republican universalism' (Chabot and Duyvendak 2002: 721). As Christophe Broqua explains in his analysis of ACT UP Paris, it was the articles of the journalist Didier Lestrade, in the gay magazine GaiPied and the daily Libération, that made the French public aware of ACT UP New York and its actions (2005: 66). Lestrade founded ACT UP Paris with two of his colleagues, and imported new repertoires of action onto the Parisian streets, such as die-ins (Broqua 2005: 71). Their connections with the USA were so clear that in their first appearance in the Parisian Gay Pride of 1989, ACT UP members had ordered their 'SILENCE = DEATH' T-shirts from New York. ${ }^{7}$ Trips to New York, as well as various press articles on ACT UP New York and ACT UP London, created the space for the introduction of street-based sexual activism in Paris. ${ }^{8}$ Although none of the above-mentioned groups utilized 'queer' as a mobilizing identity, ACT UP created the space for a new style of politics to emerge: angry in its discourse and confrontational in its tactics against the state and other institutions. This activist style later got expanded to movements explicitly identifying as queer.

\section{'Queeruptions' and the global justice influences of queer politics}

The funny thing is that there had been a Queeruption in Berlin. [...] And I was still together with R. and he was a little a bit involved. So funny, because on that weekend that I was going on this training during Queeruption, that was a training on queer education and, for example, someone gave us an introduction into queer politics. So, I preferred the intellectual approach, hearing about queer activism, instead of actually being part of it. (Vabbi, Berlin, 2011)

Listening to the stories of queer activists feels as if the whole story of queer politics is unfolding. Vabbi was born in 1980 in Eastern Germany. He participated in the Queeruption festival of 2003 in Berlin and in the Queeruption

7 'SILENCE = DEATH' was an exemplary slogan of ACT UP New York.

8 For a detailed analysis of the diffusion process of ACT UP New York to Paris, see Broqua (2005), pp. 66-73.

9 The list of the names, the status, the gender identifications, and the ages of the participants can be found in the Appendix. Names are modified. 
festival of 2005 in Sydney, many years before the QuEar festival where I met him took place. At the Queeruption in Berlin, he was not strongly involved, but had a contact through his ex-partner, who was in the organizing committee. It was mostly in Sydney, where he spent one year on a university exchange programme, that he got actively involved in Queeruption:

But I'm not sure if I knew before Sydney that Queeruption was in London and people squatted a house to party. So, the idea of linking queer activism and Queeruption with squatting, I think that was new to me in Sydney' (Vabbi, Berlin, 2011).

Vabbi's personal story on squatting and queer politics in Berlin and in Sydney is part of a broader history of queer festivals and queer collective action that has been taking place since the late 1990s, and coincided fruitfully with the rise of the global justice movement. By the end of the 199os, many European and American sexual-identity groups aligned with anarchist and anti-capitalist strands of the global justice movement, emerging at that moment (Brown 2015; Portwood-Staser 2010: 487). In 1998, activists from the anarchist scene of London organized the first Queeruption festival, which would establish an annual transnational gathering of 'queer' people that would last until 2010. This is how Queeruption presented itself in 2010, just before shutting down:

We hope this site will convey the diversity of queer life, identity, and politics; provide visibility for a definition of queer that confounds and contradicts the limited representation of the 'normal'/consumerist model; and be an active tool for building community that recognises the differences in queerness globally.

In the 200os, Queeruption festivals took place in different cities (New York, San Francisco, London, Berlin, Amsterdam, Sydney, Barcelona, Tel Aviv, Vancouver), establishing a transnational network, with an electronic platform and a mailing list. Within this list, apart from the organizational strategies and the actions, identity issues were debated, while topics such as islamophobia and racism were at the frontline of the discussions.

Europe played a main role for Queeruption festivals because many of them took place in European cities. These events had clear links with the global justice movement, which was developing during that period, too. Gavin Brown acknowledges that Queeruption festivals were spaces which have been inspired by the anti-capitalist networks of the global justice 
movement' (2007: 2685). Equally, Saskia Poldervaart saw queer politics as intersecting with feminism, through global justice transnational networks such as NextGenderation, as well as the global justice-inspired feminist collective Karakola in Madrid, which worked on the intersections of gender, queerness, and precarity. Both collectives participated in the European social forums of London and Paris (Poldervaart 2006: 14). Moreover, queer politics in Europe took the form of pink blocs in global justice demonstrations (Juris 2008b: 74), while queer groups participated in the European social forums (Doerr 2007: 82). Membretti and Mudu acknowledge, for instance, that at the demonstration against the $27^{\text {th }}$ G8 Summit in Genoa in 2001, 'the presence of various blocks oriented towards different uses of space for demonstrating', one of those being the 'queer/spectacular', was evident (2013: 88).

Although the links between Queeruption festivals and the global justice movement were more explicit, precisely because they were developing during the same period and inside the same social movement scenes, current queer festivals have more fragmented links to that history. This can be explained by the new generation of activists who compose these festivals and did not take part in the global justice movement. In this context Membretti and Mudu's frame helps us understand the ongoing legacy of the global justice movement and of Queeruption on queer festivals. They analysed the way in which Italian centri sociali [community centres] were used as a resource infrastructure for the global justice movement (Membretti and Mudu 2013: 89 ). The resources used by the Italian community centres for the global justice movement coincide with the same types of resources that are used nowadays by queer festivals. These resources are divided in five categories: 1 public places (including squatted places);

2 social networks (including cyberspace);

3 decisional processes (self-management/non-hierarchical relationships);

4 repertoires of action (symbolic representation, collective use of space);

5 codes of communication (performative power, underground culture).

Queer festivals have used all these resources created and circulated over the last fifteen years, which suggests that, to a certain extent, the legacy of the global justice movement is still with us. More specifically, I look at the global justice resources and attempt to link them with queer festivals as follows: Public places: The organization of the festivals in squats belonging to the broader anti-authoritarian domain of their cities keeps up the tradition of autonomous and horizontal political events. The spaces are open to a 'wider public of "users", offering the platform for other movements' organizations and actors to coordinate (Membretti and Mudu 2013: 89). 
The organization committees pay particular attention to the creation of 'safe spaces', in other words, there is the normative assumption that the festivals should function as places where participants would be able to express themselves without fear, threat or violence based on their gender, sexuality or other characteristics. Organizers usually achieve this without resorting to specialized professionals, opting rather for the DIY (Do-It-Yourself ) mode. Furthermore, it is also possible for participants in the festivals to reorganize the spaces on their own initiative. Based on the DIY ethos, the organizers tend to call on participants to contribute according to their skills.

Social networks: Queer activists organizing the festivals draw upon a specific network capacity, both at the local and at the international level, in order to attract their publics. Their local connections are mostly with some local LGBT actors, as well as with the local anti-authoritarian/ anarchist/squatting scenes of their cities. At the international level, networks develop between other queer platforms, social media and other queer festivals, through activist and affect/friendship relationships.

Decisional processes: At the organizational level, queer festivals have been inspired by the horizontal structures and consensual decision-making 'inherited' by the global justice movement. Queer activists themselves call this organizing mode 'flat structure'.

Repertoires of action: The queer festival forms part of the repertoire of action of the local and transnational queer communities. It also functions as a platform where other actions are discussed, decided on and performed, such as demonstrations, kiss-ins, etc. In addition, a process of mutual learning can take place, especially within technical workshops. Examples are: bike repairing, handmade sex toys, collective cooking, dragging and other similar activities, which require technical rather than theoretical skills. The transmission and sharing of practical skills constituted a big part of the autonomous mode of organization in the global justice movement (Pickerill and Chatterton 2006: 738).

Codes of communication: The global justice movement promoted 'values related to communication in an open space, networking, respect for diversity, equal participation and inclusiveness' (Della Porta 2013a: 337). This discourse on 'inclusion' is largely diffused and developed within the festivals. Its application, however, can escalate into a dispute. Regarding language and other cultural practices (food, clothes, etc.), these conform to the 'performative' character and the 'underground culture' from which certain global justice codes of communication also derive (Membretti and Mudu 2013: 89). 
The above resources, although not directly transmitted to current queer festivals, have been also part of the spread of innovative tactics and transmissions of new ideas (Ayoub 2016: 7). To that extent, the global justice movement seems to have fertilized the ground for future queer actions. To sum up, queer festivals draw upon histories that connect to various sources, such as US-based queer activism, academic queer theory, but also global justice and Queeruption movements histories. In queer festivals' contextualization, however, another crucial parameter needs to be addressed: their sociological composition.

\section{Subordinate discourses rather than positions: Sociological indications of queer festivals}

I shift now the focus to sociological trends of queer festivals' activists and participants, in order to complete the picture of their contextualization before moving to the discussion on the construction of queer anti-identitarian identities. In the start of my fieldwork, I wondered whether queer festivals were arenas in which 'some ostensible members of a subordinated group may have attained positions of privilege in relation to their cohorts' (Asen 2000: 439). In other words, I set two sociological hypotheses. First, I assumed that the large majority participating in the festivals assert identification with non-heterosexual identities, and this makes them susceptible to subordinate positions because of their sexuality. Second, I assumed that education or class might have balanced to some extent the previous subordination.

According to the results of the online survey I conducted at the Oslo Queer Festival, ${ }^{10}$ my initial hypotheses were confirmed. A large majority of the respondents had acquired privilege through other social processes, such as education or social status, although actors with lower social status appear in the responses, too. The most illustrative indication of the survey relates to the self-identification of respondents relating to their social background. Thus, $74 \%$ replied that they came from families which would be defined as 'middle-class', $14 \%$ replied that they came from upper-middle-class families, while only $12 \%$ claimed to come from lower-middle-class backgrounds. ${ }^{11}$ Concerning the financial situation of the activists and the participants in

10 See the Appendix for further information on the survey.

11 The question was posed in this form: 'How would you describe your family's monthly income when you were 17 years old?' In the attempt to objectify the replies and not rely on subjective identifications, I provided respondents with possible replies corresponding to seven income categories, based on the average income per capita scheme as provided by OCDE 'Better Life Index', http://www.oecdbetterlifeindex.org/countries/norway/ (last accessed: 08/11/2016). 
the festival, $52 \%$ asserted they worked part-time, $32 \%$ worked full-time ( 40 hours and more per week), and only $12 \%$ were not employed and not looking for job. The remaining $4 \%$ declared themselves unable to work due to issues regarding physical disability. We observe a continuation between financial stability and social background, characteristics of middle-class belonging. Concerning the quality of jobs, the question was open. Thus, respondents identified themselves, giving their own titles to their jobs. According to the results, I regrouped them into eight categories:

\section{Table 2.1 Jobs of people participating in the 2011 Oslo Queer Festival and rates}

\begin{tabular}{ll}
\hline $\begin{array}{l}\text { Jobs categories of the participants and of } \\
\text { the organizers }\end{array}$ & $\begin{array}{l}\text { Rate among those who responded to the } \\
\text { questionnaire }\end{array}$ \\
\hline $\begin{array}{l}\text { High-skilled profession (manager, advisor, } \\
\text { consultant, IT architect) }\end{array}$ & $21.7 \%$ \\
Student & $17.4 \%$ \\
PhD researcher/researcher & $17.4 \%$ \\
& \\
Low-skilled profession (bartender, janitor, & $13 \%$ \\
bike mechanic) & \\
Care/social worker & $8.6 \%$ \\
Artist & $8.6 \%$ \\
Teacher & $4.3 \%$ \\
Volunteer & $4.3 \%$ \\
\hline
\end{tabular}

High-skilled tertiary jobs account for more than $80 \%$ of the total respondents. On the contrary, lower skilled jobs, and people who failed to reply account for approximately $20 \%$.

The educational position of the respondents is equally illuminating. To the question 'What is the highest level of school you have completed or the highest degree you have received?', $60 \%$ of the respondents affirmed that they held a university degree at the time of the survey. Among these, $36 \%$ held a bachelor's degree and $24 \%$ a post-graduate degree. The high level of education serves to verify the observation of the high cultural capital that many of the participants in the festivals enjoy. Predominantly young $(96 \%$ were between 21 and 39), more than half of queer participants at the Oslo Queer Festival were finally between 21 and 29 years old (56\%).

Since the sample is taken from Oslo, the results concerning professional stability cannot be automatically generalized to the other queer festivals, especially in those cities where a high degree of youth unemployment is structurally constraining, such as in Rome or in Berlin. For instance, in the 
survey, no respondent claimed to be looking for a job, certainly thanks to the high employment rates that Norway enjoys. We could, however, be more confident in generalizing the results with reference to family background and cultural capital acquired through education, confronted with qualitative observations in the fieldwork.

The above-mentioned interpretations do not contradict the findings on the global justice movement's constituency, and give us once more the confirmation of the global justice movement's sociological continuity in current queer festivals. Thus, according to Gobille and Uysal's analysis of the European Social Forum (ESF) in Paris, its participants were in the majority young (less than 35 years old), holding a high degree of cultural capital, and profiting from a relatively stable professional position (2005: 107). Finally, the demographics of festivals' sociological constituency is not far from the one of new social movements activists who initiated identity politics in Europe (Offe 1985).

\section{Conclusion}

This chapter contextualized the origins of queer festivals in their historical and sociological settings. The legacies of European queer festivals were discussed by tracing them back to US-based queer activism and queer theory, as well as the global justice movement and its resources. Moreover, the importance of the Queeruption festivals as the precursor of what would establish queer festivals in Europe was acknowledged. Finally, I attempted a sociological contextualization through the online survey I conducted on the Oslo Queer Festival's participants. The young and educated profile of queer festivals was confirmed, and this finding links back to the global justice and new social movements' legacy, in which similar socio-demographics were identified, too. What is the impact of these legacies and of these profiles in the arrangements of the practices and discourses of queer festivals' identitybuilding will be explored in Chapters 3, 4 and 5. The next chapter unfolds the discussion, by discussing a crucial parameter of queer identity-building: space and organizational activities. 
